\title{
"BIEN VESTIDO COMO MAL VESTIDO" CIVILIZACIÓN Y CULTURA EN "EL LICENCIADO VIDRIERA"
}

\author{
Eva Cruz García \\ Universidad de Alcalá de Henares
}

¿Por qué el Licenciado Vidriera no encuentra trabajo después de recuperar la cordura? Su extraña locura destruyó irremisiblemente la confianza de los demás en él ("tan bien puede ser loco bien vestido como mal vestido," decían). La locura de Tomás Rodaja es distinta de la de Alonso Quijano no sólo en las características del delirio, sino también en sus consecuencias para el paciente: mientras que don Quijote finalmente muere tranquilo en su casa, habiendo recuperado el respeto de sus semejantes, el Licenciado Rueda se ve obligado a abandonar la vida a la que tanto esfuerzo había dedicado sin lograr ejercer como abogado. Especializarse en leyes en el Barroco suponía convertirse en orador, una figura que, según la tradición clásica encarnada por Cicerón, constituía el uir ciuilis por excelencia. Pero el Licenciado Vidriera no logra, a pesar de su dedicación casi fanática al estudio, más que convertirse en un bufón aislado y sin amigos, tanto bien vestido como mal vestido. Aquí me propongo dar alguna idea sobre qué es exactamente lo que se ha quebrado tan trágicamente en el camino de la vida de Vidriera.

Desde un punto de vista literario podríamos decir que Cervantes utiliza la figura del loco con tanta frecuencia porque la relación entre el loco y el mundo es extraordinariamente similar a la que se establece entre la literatura y la vida. Los delirios de Alonso Quijano y de Tomás Rodaja sobre sí mismos no les impiden decir "la verdad" acerca del mundo en el que viven. Así, la sátira social y moral a la que dan voz es siempre oblicua, en el sentido de que llega siempre desde un ángulo imprevisto, que ilumina nuevamente lo ordinario. Ocurre lo mismo en el caso de la ficción que, por su propia naturaleza, raramente puede decir "lo que dice" de manera directa. Por esta razón la figura del loco resulta tan literaria. En este sentido, se ha convertido ya prácticamente en un lugar común de los estudios de literatura comparada el análisis conjunto de El Elogio de la Locura de Erasmo, por un lado, y el Quijote y El Licenciado Vidriera, por otro. Aquí me propongo, a través del trabajo del sociólogo Norbert Elias, hacer una nueva lectura de la novela corta cervantina conectándola esta vez con otro texto del intelectual holandés, quizá menos sugerente, y bastante olvidado por los estudiosos del erasmismo en España: De Ciuilitate Morum Puerilium. 
Una posible explicación a por qué el Licenciado Rueda no encuentra trabajo después de recuperar la razón es que su locura supone una escisión entre la civilización y la cultura, que el Licenciado Vidriera es un hombre culto pero que ha perdido la condición de hombre civilizado. El resultado de este divorcio es monstruoso, y sólo puede ser descrito como locura: el sujeto se ha vuelto inclasificable. Es Norbert Elias quien ofrece, partiendo de una explicación histórica que él denomina sociogénesis, la definición más útil de lo que es civilización y lo que es cultura según la tradición alemana, que es muy distinta a la francesa, la inglesa, y la española, heredera de éstas últimas:

for the [English and French] the concept [of civilisation] sums up the single term for their pride in the significance of their own nations for the progress of the West and of mankind. But in German usage, Zivilisation means something which is indeed useful, but nevertheless a value of the second rank, comprising only the outer appearance of human beings, the surface of human existence. The word through which Germans interpret themselves, which more than any other expresses their pride in their own achievement and their own being, is Kultur.

$\left(1994\right.$, p. 4) ${ }^{1}$

Lo civilizado, por tanto, se refiere sólo a la "apariencia exterior de los seres humanos, a la superficie de la vida." En este sentido nos recuerda al adjetivo español "civil", que, en una acepción infrecuente, "se aplica [y cito el diccionario de María Moliner] a las personas que se comportan debidamente en sus relaciones con otras y a su comportamiento, maneras, etc." Y nos envía a adjetivos como "amable, "correcto", "cortés", "educado" y "sociable". Es a este sentido al que me refiero cuando digo que el Licenciado Vidriera no es un hombre civilizado, aunque pueda ser descrito como un hombre culto. Es evidente, además, que esta definición de civilización establece claramente la diferencia fundamental entre el trastorno de don Quijote y el del Licenciado Vidriera. Don Quijote ha perdido la razón, sí, pero no su condición de hombre civilizado.

Es precisamente en el siglo XVI cuando los buenos modales empiezan a regularse de manera más coercitiva, entre otras razones porque los largos periodos de paz contribuyen a la formación de una nueva aristocracia que no está basada ya en la potencia militar, y que necesita por tanto definir su comportamiento en términos más precisos, para limitar el ascenso social de unos individuos que ven en la nueva época aperturas nuevas para su ambición. Por esta razón, cuanto mayor es la difusión de las nuevas normas de comportamiento social, más estrictas se vuelven estas normas, dis-

1. En el trabajo he utilizado la mayoría de las fuentes en su versión inglesa. Citaré, por tanto, en inglés, y proporcionaré mis propias traducciones en notas al pie del texto: "Para los [ingleses y franceses] el concepto [de civilización] resume en un solo término su orgullo por el significado de sus propias naciones para el progreso de Occidente y de la humanidad. Pero para los alemanes, Zivilisation significa algo que es sin duda útil, pero que supone un valor de segunda clase, referido sólo a la apariencia exterior de los seres humanos, a la superficie de la existencia humana. La palabra a través de la cual los alemanes se interpretan a sí mismos, la que más que cualquier otra expresa su orgullo por sus propios logros y por su propio ser, es Kultur." 
minuye el umbral de lo permisible, aumenta el espectro de lo que ha de cubrir el pudor. Elias explica que "the question of uniform good behaviour becomes increasingly acute, particularly since the new upper class exposes each individual member to an uprecedented extent to the pressure of others and of social control. It is in this context that the writings on manners of Erasmus, Castiglione, Della Casa, and others are produced. People, forced to live with one another in a new way, become more sensitive to the impulses of others" $\left(1994\right.$, p. 64) ${ }^{2}$. Y, como apunta Elias, el texto fundamental en el que se expresa esta nueva preocupación por los límites de lo permisible, por cómo vivir armoniosamente en sociedad, es De Ciuilitate Morum Puerilium, que tuvo una extraordinaria repercusión en Europa, llegando a las treinta reimpresiones en seis años, de 1530, año de su publicación, a 1536, año de la muerte de Erasmo. Sin querer entrar en disquisiciones acerca de la influencia directa de Erasmo sobre Cervantes, lo que sí me parece importante destacar es la probabilidad de que ambos textos nazcan de una preocupación común sobre los límites y las idiosincrasias de los conceptos de civilización y cultura que se estaban construyendo en la época moderna.

Elias señala que las circunstancias de producción de De Civilitate lo convierten en un libro cuyos preceptos carecen de una orientación social específica, a diferencia de lo que le ocurre a sus sucesores, especialmente en las tradiciones italiana y francesa (1994, p. 61). Erasmo manifiesta, según Elias, "the characteristic self-confidence of the intellectual who has ascended through knowledge and writing, who is legitimized by books, the self-assurance of a member of the humanistic intellectual class who is able to keep his distance even from ruling strata and their opinions, however bound to them he may be" $\left(1994\right.$, p. 59) ${ }^{3}$. También Tomás Rodaja manifiesta durante la novela su independencia feroz de cualquier tipo de atadura institucional o emocional que no sirva a su ambición de convertirse en un intelectual, confiado en que el estudio lo hará libre y próspero. Recordemos un fragmento de la dedicatoria de Erasmo al joven príncipe Enrique de Borgoña: "Let others paint lions, eagles, bulls, and leopards on their escutcheons; those who can display 'devices' of the intellect commensurate with their grasp of the liberal arts have a truer nobility” (1982, p. 274)4. También Rodaja prefiere la vida de las letras a la vida de las armas, a pesar de que caiga finalmente en la vida

2. "el problema de la uniformidad del buen comportamiento se vuelve cada vez más agudo, especialmente porque la nueva clase alta expone a cada individuo a un nivel de presión por parte de otros y de control social sin precedentes. Es en este contexto en el que se producen los escritos sobre urbanidad de Erasmo, Castiglione, Della Casa, y otros. Las personas, obligadas a vivir unas con otras de una manera nueva, se vuelven más sensible a los impulsos de los demás."

3. "la confianza característica del intelectual que ha ascendido a través de los conocimientos y de la escritura, que se legitima a través de los libros, la seguridad en sí mismo de un miembro de la clase intelectual humanista que puede mantener incluso una cierta distancia con respecto de la clase gobernante y de sus opiniones, por muy ligado a ellas que esté."

4. "deja que otros pinten leones, águilas, toros y leopardos en sus escudos; los que son capaces de mostrar emblemas del intelecto según su aprehensión de las artes liberales son poseedores de una nobleza más verdadera." 
de soldado a falta de otra oportunidad laboral. Es posible que Vidriera estuviera respondiendo a esta nueva percepción de la independencia intelectual y de las posibilidades de ascensión social que había encarnado Erasmo en un tiempo en que las fronteras sociales estaban en un periodo de renovación y de confusión en el que aún se podía afirmar, como hace Erasmo, que "no one can choose his own parents or nationality, but each can mould his own talents and character for himself" (1982, p. 289)5. Pero, como bien señala también Elias, esta época duró muy poco tiempo, y para cuando surge el Licenciado Vidriera, en 1613, las cosas habían cambiado, en España particularmente, a causa de la Contrarreforma, pero en el resto de Europa también:

in the period immediately after Erasmus's time, few people would have had the assurance or even the social opportunity to express such thoughts openly in a dedication to a noble. With the increasing stabilization of the social hierarchy, such an utterance would have been increasingly seen as an error of tact, perhaps even an attack. The most exact observance of differences in rank in behaviour becomes from now on the essence of courtesy, the basic requirement of civilite, at least in France. The aristocracy and the bourgeois intelligentsia mix socially, but it is an imperative of tact to observe social differences and to give them unambiguous expression in social conduct.

$(1994$, p. 59) 6

Sea como fuere, Tomás Rodaja a los once años está convencido de que "de los hombres se hacen obispos" (1982, p. 104), razón por la que ha decidido irse a Salamanca, donde espera encontrar un amo que le permita estudiar, puesto que desea honrar a sus padres y a su pueblo (dos circunstancias que declara no recordar) a través del estudio. Es de camino a esta ciudad universitaria donde le encuentran dos caballeros estudiantes durmiendo bajo un árbol. Como señala Juan Bautista Avalle-Arce, Cervantes juega desde el principio con las expectativas del lector barroco, ofreciendo una apertura propia de novela de caballerías. Esta tradición habría exigido que al final de la novela Tomás hubiera vuelto a su casa después de honrar a su anónima familia, o bien que el personaje, o el lector, o ambos, hubieran descubierto un origen de alcurnia que no hiciese sino añadir más gloria a la gloria que le esperaba a través de los libros, o la guerra, o el amor. Pero en lugar de seguir ese camino, de volver a cincelar una novela ya escrita y

5. "nadie puede elegir a sus padres, ni su nacionalidad, pero cada uno puede modelar sus propios talentos y su propio carácter por sí mismo."

6. "en el periodo inmediatamente posterior al de Erasmo pocos habrían tenido la confianza o incluso la oportunidad social de expresar pensamientos como éstos abiertamente en una dedicatoria a un noble. Con la estabilización creciente de la jerarquía social, una frase como ésa se hubiera visto cada vez más como un error de tacto, incluso como un ataque. La observancia estricta de las diferencias de rango en el comportamiento se convierte de ahora en adelante en la esencia de la cortesía, el requisito básico de la civilité, al menos en Francia. La aristocracia y la intelligentsia burguesa se mezclan socialmente, pero observar las diferencias sociales se convierte en un imperativo del tacto, así como darle a estas diferencias una expresión en la conducta que no deje lugar a ambigüedades." 
halagar la experiencia del lector, Cervantes decide forzar al lector, obligándole a preguntarse por el error del Licenciado Rueda, a buscar las razones de su fracaso. Y, como apuntábamos antes, muchos lectores y críticos lo encuentran en la independencia despiadada de Rodaja, a quien, a pesar de sus penurias, ni se le ocurre volver a casa de sus padres, o porque no los tiene o, lo que es peor, no quiere tenerlos, como no querrá tampoco tener patria, ni camaradas (sólo acepta unirse a don Diego de Valdivia con la condición de que "no se había de sentar debajo de bandera, ni poner en lista de soldado, por no obligarse a seguir su bandera", 1982, p. 107) ni mujer ("como él atendía más a sus libros que a otros pasatiempos, en ninguna manera respondía al gusto de la señora" 1982, p. 115). Este principio de misantropía de Rodaja se manifiesta, al convertirse el personaje en Vidriera, en una crítica fragmentada pero voraz de todos los estamentos sociales, a excepción de los buenos poetas de los que "siempre dijo bien y levantó sobre el cuerno de la luna" (1982, p. 125). En opinión de Ruth El Saffar Cervantes comete un error al hacer que la locura de su personaje se vea desencadenada por el membrillo envenenado que le ofrece la mujer, ya que existe una unidad fundamental entre Rodaja y Vidriera que Cervantes nubla al introducir el veneno para explicar la transformación (1974, p. 56). Para esta crítica "the fear of physical suffering, the will to isolate himself from others, and the exaggerated importance ascribed to mental activity are elements of the Licentiate's personality present from the beginning" (1974, p. 57)7.

Para el crítico español J. R. Sampayo, sin embargo, el membrillo simboliza el fruto que Eva le ofreció a Adán, interpretando así "El Licenciado Vidriera" como una relectura del mito de la caída del hombre y del pecado original:

En el mito bíblico, ¿no fue un acto de locura la desobediencia ciega de Adán al mandato divino? Y ese acto de locura, ¿no consistió en la pretensión y el deseo de ser "como Dios"? Pero el castigo que le infringió Yavé, ¿no fue la más extraña locura" que pudo padecer el entendimiento del hombre? Al arrojarlo del jardín del Edén su vida dejó de ser inmortal: su cuerpo se convirtió en polvo (en vida y muerte), la más inconsistente materia de la tierra; tuvo que luchar en una naturaleza salvaje, donde él era el más débil y desasistido de los animales que la poblaban y sólo su superior entendimiento podía hacerle sobrevivir y triunfar sobre ellos. Pues bien, en el caso del Licenciado Vidriera, Dios permite la actuación demoníaca de la mujer "de todo rumbo y manejo", y la naturaleza -"mayordoma del verdadero Dios", como la califica el mismo Cervantes en el Persiles- es la encargada de castigar mediante el fruto envenenado el mal de culpa del Licenciado.

El castigo de la naturaleza, que refleja la voluntad divina de poner límites a la sabiduría humana, pone fin a una forma de vida que se había ido deslizando intelectual y espiritualmente, cada vez más, hacia el conocimiento de las verdades esenciales del hombre, es decir, hacia el dominio cognoscitivo pleno de las leyes que rigen la vida humana. El Licenciado Tomás deseó tan intensamente

7. "el miedo al sufrimiento físico, el deseo de aislarse de los demás y la importancia exagerada que se le da a la actividad mental son elementos de la personalidad del Licenciado presentes desde el principio." 
"subir por su pie al cielo, o volar con alas (las de la sabiduría humana), o ser una
estrella" (que iluminase a todos los hombres y clases sociales) que llegó a con-
vertirse en el más frágil de los hombres, en el Licenciado "Vidriera". Fue el cas-
tigo merecido a su pecado de culto absoluto a la inteligencia.

(1986, pp. 73-4)

He citado esta interpretación de modo tan extenso porque parece impecable, pero tengo algunas objeciones basadas en mi opinión de que el relato cervantino permite más lecturas que la religiosa. Para empezar, la sabiduría a la que aspira el Licenciado es de naturaleza absolutamente prosaica. En este sentido estoy de acuerdo, además, con el crítico Paul Julian Smith, que sugiere que las listas (perfectamente banales) de las que se compone la parte de la novela que narra los viajes por Italia y Flandes del Licenciado podrían ser un recurso estilístico destinado a simular el proceso de aprendizaje habitual en esta época: la memorización de lugares comunes que pudieran servir posteriormente para la elaboración e improvisación de discursos o sermones (1988, p. 186). El pecado de Vidriera podría ser uno de ambición desmedida, pero desde luego no se le puede castigar porque se estuviera acercando al "dominio cognoscitivo de las leyes que rigen la vida humana". No creo que eso lo justifique el texto, como tampoco me parece que justifique la afirmación de que el castigo de Vidriera es merecido: Cervantes busca, me parece, que el lector sienta, como los ciudadanos que observan a Vidriera, "lástima y admiración". Roberto Ruiz afirma, en este sentido también, que "los pasajes donde se describe la incomodidad de las naves, la abundancia de los vinos, la belleza de las villas y comarcas, no representan opiniones o hallazgos de Tomás, sino dictámenes comunes, acreditados "a priori” (1985, p. 841). Como venimos diciendo, el pecado de Vidriera reside más bien en su falta de sociabilidad, en su rechazo a los vínculos afectivos, en su carencia, si se requiere una explicación religiosa, de pietas cristiana.

Para E. C. Riley, como para muchos otros críticos, la figura de Vidriera está influida por la de los filósofos de la escuela cínica, con quienes el personaje cervantino comparte una serie de características fundamentales: el desprecio por la vestimenta, por las posesiones y por la higiene, el gusto por la crítica feroz, la dependencia egoísta de la caridad ajena, la costumbre de comer y dormir en lugares públicos, el rechazo, en fin, de lo que Riley llama "the traditionally esteemed ornaments of civilization" (1976, p. 192)

La locura del Licenciado, por tanto, se basa no sólo en una deficiente y obsesiva percepción de sí mismo, sino también en el rechazo a las normas básicas de relación social que emana de esta obsesión por su cuerpo. Decir que el Licenciado ha perdido toda noción de urbanidad parece una afirmación tan banal como la propia idea de urbanidad. Pero, como demuestra Elias, la noción de urbanidad, de buenos modales, encierra elementos clave sobre cómo el ser humano se relaciona con sus semejantes,

8. "los ornamentos de la civilización tradicionalmente estimados." 
sobre lo privado y lo público, sobre el pudor y el cuerpo, sobre lo que, siendo común, nos esforzamos en mantener oculto. El Licenciado establece una relación impúdica con su cuerpo, en la que éste determina absolutamente su existencia. Erasmo plantea la relación con el propio cuerpo como una jerarquía sencilla: "external decorum of the body proceeds from a well ordered mind" (1982, p. 273)9. Pero también sabe que estas afirmaciones basadas en el sentido común deben ser desglosadas, porque el control del propio cuerpo en realidad es algo que debe aprenderse. Así, la primera parte del tratado se ocupa, de manera tan pormenorizada que resulta incluso cómica, en lo siguiente: cómo mirar, cómo colocar las cejas, qué hacer con los orificios nasales, con las mejillas, la boca, los dientes, el pelo, con las piernas al sentarse, al caminar, al inclinarse, cómo controlar los estornudos y los bostezos, cómo disimular todos los demás movimientos involuntarios del cuerpo. No atender a estas reglas fundamentales se considera una señal, no sólo de falta de educación o de rusticidad imperdonable, sino también de una mente enajenada. Y el Licenciado, recordemos, tiene tal descontrol sobre su propio cuerpo que cuando la gente se le acercaba a abrazarle para probar que no era de vidrio en absoluto "el pobre se echaba en el suelo dando mil gritos, y luego le tomaba un desmayo del cual no volvía en sí en cuatro horas; y cuando volvía era renovando las plegarias y rogativas de que otra vez no le llegasen" (1982, p. 117). "Abrazarle” es, para mayor abundamiento, la palabra que utiliza Cervantes.

Cervantes se detiene también a lo largo de todo el relato en la ropa que lleva puesta su personaje en las distintas etapas de su vida. Al encontrarle los caballeros estudiantes se dan cuenta de quién es, dentro del escalafón social, porque va "vestido como labrador" (1982, p. 103). Nada más llegar a Salamanca, Cervantes nos informa de que se vistió todo de negro, para hacer saber a quien le viera que era estudiante. Y al unirse a don Diego de Valdivia se viste "de papagayo, renunciando a los hábitos de estudiante, y púsose a lo de Dios es Cristo, como se suele decir" (1982, p. 197). Pero es en su transformación más radical, la de volverse loco, la que le hace vestir un uniforme que es una amenaza para la decencia y que le marca tan irremisiblemente que, al recuperar la cordura, la gente ya no puede evitar comentar con suspicacia que "bien puede ser loco bien vestido como mal vestido": "Pidió Tomás que le diesen alguna funda donde pusiese aquel vaso quebradizo de su cuerpo, porque al vestirse algún vestido estrecho no se quebrase; y así le dieron una ropa parda y una camisa muy ancha, que él se vistió con mucho tiento y se ciñó con una cuerda de algodón. No quiso calzarse zapatos en ninguna manera" (1982, pp. 117 8). La segunda parte del tratado de Erasmo sobre urbanidad se refiere precisamente al vestir, "because clothing is in a way the body's body, and from this too one may infer the state of a man's character" $\left(1982\right.$, p. 278) ${ }^{10}$. Erasmo afirma con irreprocha-

9. "el decoro externo del cuerpo procede de una mente bien ordenada."

10. "porque el vestido es, de alguna manera, el cuerpo del cuerpo, y de él puede inferirse también el estado del carácter de un hombre." 
ble sensatez que "style of dress should be in accordance with one's means and station, neither conspicuous by its shabbiness nor indicative of opulence" (1982, p. 279) ${ }^{11}$. Cervantes deja muy claro que el pobre Licenciado, cuando loco, va hecho unos zorros.

Inmediatamente después la novela se adentra en una explicación de cómo se las arregla el Licenciado para comer: "el orden que tuvo para que le diesen de comer sin que a él le llegasen fue poner en la punta de una vara una vasera de orinal, en la cual le ponían alguna cosa de fruta de las que la sazón del tiempo ofrecía. Carne ni pescado, no lo quería; no bebía sino en fuente o en río, y esto con las manos" (1982, p. 118). La cuarta parte del manual de Erasmo, tras una sección dedicada a cómo ha de proceder uno en la iglesia, trata del comportamiento durante las comidas. Por ser éstas las ocasiones sociales por excelencia Erasmo le dedica la parte más extensa del texto. Pero, como hemos visto, Vidriera come en soledad y sin hacer uso de ninguno de los adelantos que ofrece la civilización: sólo alimentos de temporada, y éstos sin cocinar, y sin sentarse a una mesa, ni usar cubiertos ni vasos. El Licenciado come como un animal. Y, por supuesto, también duerme en pajares y en lugares públicos, como un salvaje. Curiosamente, la última parte del tratado de Erasmo es sobre el comportamiento que uno ha de observar en el dormitorio. Para establecer una relación aún más obvia entre su personaje y una criatura no civilizada Cervantes añade que al Licenciado le asustan las tormentas. Como a los perros.

Hemos visto que Cervantes sigue en su descripción de la locura de su personaje un orden muy similar al que utiliza Erasmo en su tratado de urbanidad. Y, efectivamente, Erasmo añade, a modo de postdata el que es, a su parecer, el mayor crimen contra los buenos modales: "the essence of good manners consists in freely pardoning the shortcomings of others although nowhere falling short of yourself" (1982, p. 289) ${ }^{12}$. Y es en esto en lo que falla estrepitosamente Vidriera, en su ensañamiento implacable contra todos y contra todo.

Es evidente que el proceso educativo que ha seguido el Licenciado no da los resultados que se esperaban. En su afán por adquirir cultura, Tomás Rodaja parece haber olvidado, como Steven Guazzo, otro famoso intelectual melancólico de la época, el verdadero objetivo de la vida intelectual, que no es otro que la vida civil:

In the Renaissance, cultus or cultura was commonly associated with the cultivation of literature, philosophy, eloquence, law, arts and sciences, whose fruits were the human and civic virtues necessary for civil society (...). 'True culture'

11. "el estilo del vestido debe estar en concordancia con los medios y la posición de uno, que ni llame la atención por lo desaliñado, ni que sea señal de opulencia."

12. "la esencia de los buenos modales consiste en perdonar libremente los defectos ajenos sin por ello fallar uno mismo." 
(vera cultura) was an indication of morality, sociability and advancement from a primitive or natural state.

(Donald R. Kelley, 1996, p. 101) ${ }^{13}$

Cervantes parece muy consciente de esto en su lúcido prólogo a las Novelas Ejemplares, donde dice claramente cuál es su intención:

Mi intento ha sido poner en la plaza de nuestra república una mesa de trucos, donde cada uno pueda llegar a entretenerse, sin daño de barras; digo sin daño del alma ni del cuerpo, porque los ejercicios honestos y agradables, antes aprovechan que dañan.

Sí, que no siempre se está en los templos; no siempre se ocupan los oratorios; no siempre se asiste a los negocios, por calificados que sean. Horas hay de recreación, donde el afligido espíritu descanse.

Para este efeto se plantan las alamedas, se buscan las fuentes, se allanan las cuestas y se cultivan, con curiosidad, los jardines.

(1982, p. 64)

Su intención tiene que ver con el ocio, es complementaria de la piedad y de los negocios, es un adorno, como los jardines curiosos, destinados a hacernos más agradable la vida. El Licenciado habla también de "algunos ilustres y excelentes sujetos donde resplandece la verdadera luz de la poesía que, tomándola por alivio y entretenimiento de sus muchas y graves ocupaciones, muestran la divinidad de sus ingenios y la alteza de sus conceptos" (1982, pp. 124-5). Uno de los primeros traductores de Cervantes, James Mabbe, escribe su propia dedicatoria a su traducción al inglés de seis de las doce novelas (desgraciadamente entre ellas no se encuentra "El Licenciado"). En ella es aún más explícito que Cervantes sobre el objetivo de los textos, tanto que parece incluso que le resta relevancia al esfuerzo del español, cosa que sin duda sería conveniente por motivos políticos y religiosos. Sea como fuere, Mabbe escribe:

Your wisest and most learnedst Men both in Church and Common-weale, will sometimes leave off their more serious Dicourses, and entertaine themselves with matters of harmlesse Merriment, and Disports. Such are these Stories I present to your view. I will not promise any great profit you shall reape by reading them, but I promise they will be pleasing and delightfull (...) These are but a few of running banquetting dishes.

$(1900 \text {, p. } 2)^{14}$

13. "En el Renacimiento la palabra cultus o cultura se asociaba habitualmente al cultivo de la literatura, la filosofía, la elocuencia, las leyes, las artes y las ciencias, cuyos frutos eran las virtudes humanas y cívicas necesarias para la sociedad civil. (...) La vera cultura era un signo de moralidad, sociabilidad y progreso desde un estado primitivo o natural."

14. "Los hombres más sabios y leídos de la Iglesia y la República a veces abandonan sus discursos más serios y se entretienen con asuntos de alegría inofensiva, y con juegos. Así son las historias que presento ahora. No les prometo que de su lectura vayan a obtener grandes beneficios, pero sí que serán encantadoras, y de su agrado (...) Éstos no son sino algunos de platos de un banquete." 
Las imágenes que se evocan en estas introducciones, de jardines y banquetes, de juegos y entretenimientos, podrían estar llamando nuestra atención sobre un aspecto de las Novelas Ejemplares que a menudo olvidamos en nuestra veneración de los clásicos. Creo que Cervantes se tomaba muy en serio su propia literatura, su trabajo intelectual, así como los problemas del mal leer, pero quizá, a diferencia de sus personajes, no tenía una fe desmedida en el poder de los libros, en la eficacia pública de su trabajo privado. El poeta John Donne lo expresa bien cuando en su Satyre II se queja de que sus críticas de determinados abusos resulten ineficaces porque la poesía no tiene ningún valor estatutario: "my words none drawes/ within the vast reach of th'huge statute lawes". Esto tiene que ver con lo que decíamos al principio acerca del estatus de Vidriera como crítico social, de la ficción con respecto a la vida; pero nos permite añadir además que tanto la queja de Donne como el valor de entretenimiento de las Novelas son, al fin y al cabo, actitudes de una cierta superioridad frente a la vida diaria. Uno sólo puede concentrarse en la superficie de la vida cuando tiene las necesidades básicas cubiertas, y el alma asegurada. Pero, al mismo tiempo, la superficie es la parte más elevada de las cosas. Cervantes se dirige a un lector civilizado, que tiene el tiempo y la posibilidad de pasear por alamedas. Las alamedas no se ven como una frivolidad, sino como una conquista. Y este intento declarado de Cervantes lo demuestra no sólo el prólogo, sino también la elegante presentación del volumen, la dedicatoria a don Pedro Fernández de Castro, con sus seis títulos nobiliarios dispuestos ostentosamente en la cubierta, el Privilegio de Aragón, las cuatro aprobaciones, la carta del Rey y los sonetos preliminares dedicados al autor. El hecho de que este tipo de ostentación fuera habitual en los libros de la época no diluye, sino que más bien confirma lo que venimos diciendo: que el libro como objeto es, ante todo, un icono de la civilización, y que reconocerse como el lector al que se dirige Cervantes es un gran paso para convertirse en un lector civilizado. Las capacidades que uno utiliza para escribir y para leer libros marcan además los umbrales de nuestra civilización, puesto que antes de la escritura la historia es sólo prehistoria. No ser civilizado, no participar de estas técnicas y conocimientos es casi como no ser. Por mucho que luego los contenidos de los libros puedan cuestionar o incluso rechazar los mecanismos y los resultados del proceso civilizador en curso. Por mucho que nuestra veneración por nuestras propias capacidades, por lo que nos distingue y nos hace mejores nos pueda convertir finalmente en bufones aislados y sin amigos, o incluso en salvajes.

\section{Bibliografía}

Cervantes SaAvedra, Miguel De. Exemplary Novels. Traducidas por James Mabbe (1640). Edición de S. W. Orson. Philadelphia: J. B. Lippincott Company, 1900.

Cervantes SaAvedra, Miguel De. Novelas Ejemplares. Edición de Juan Bautista Avalle-Arce. Madrid: Castalia, 1982. 
Donne, John. Poetical Works. Edición de J. C. Grierson. Oxford \& New York: Oxford University Press, 1971.

Elias, Norbert. The Civilizing Process. Oxford \& Cambridge, Mass.: Blackwell, 1994.

Erasmo, Desiderio. De Ciuilitate Morum Puerilium (On Good Manners for Boys). Traducción de Brian McGregor, en Collected Works of Erasmus. Vol. 25. Toronto: University of Toronto Press, 1982.

El Saffar, Ruth. From Novel to Romance: A Study of Cervantes's Novelas Ejemplares. Baltimore \& London: Johns Hopkins University Press, 1974.

Kelley, Donald R. "The Old Cultural History”. En History of the Human Sciences. Vol. 9, n. 3. London, Thousand Oaks and New Delhi: SAGE, 1996, pp. 101-126.

Riley, E. C. "Cervantes and the Cynics (El Licenciado Vidriera y El Coloquio de los Perros)". En Bulletin of Hispanic Studies, III (1976), pp. 189-199.

RuIz, RoBerto. "Las “tres locuras" del Licenciado Vidriera”. En Nueva Revista de Filología Hispánica, 1985-86, 34:2, pp. 839-847.

SAmpayo Rodriguez, José RAmOn. Rasgos erasmistas de la locura del Licenciado Vidriera de Miguel de Cervantes. Kassel: Edition Reichenberger, 1986.

Smith, Paul Julian. Writing in the Margin: Spanish Literature of the Golden Age. Oxford: Clarendon, 1988. 